\title{
Evaluation of Road Service Performance Based on Human Perception of Vibration While Driving Vehicle
}

\author{
Wenbo Shi $\left(\mathbb{D},{ }^{1,2}\right.$ Ming Li $\mathbb{D}^{2},{ }^{2}$ Jingxuan Guo $\mathbb{D}^{2},{ }^{2}$ and Kaixuan Zhai $\mathbb{D}^{2}$ \\ ${ }^{1}$ School of Water Resources and Environment, Zhengzhou University, Zhengzhou 450000, China \\ ${ }^{2}$ School of Traffic and Transportation, Xuchang College, Xuchang 461000, China \\ Correspondence should be addressed to Wenbo Shi; shwanbe@163.com
}

Received 14 August 2020; Revised 15 November 2020; Accepted 12 December 2020; Published 22 December 2020

Academic Editor: Sara Moridpour

Copyright (c) 2020 Wenbo Shi et al. This is an open access article distributed under the Creative Commons Attribution License, which permits unrestricted use, distribution, and reproduction in any medium, provided the original work is properly cited.

Road surface monitoring is a significant issue in providing smooth road infrastructure for vehicles, and the key to road condition monitoring is to detect road potholes that affect driving comfort and transportation safety. This paper presents a simple, efficient, and accurate way to evaluate road service performance based on the acquisition of road vibration data by vibration sensors installed in vehicles. Inspired by the discrete fast Fourier transform, the vibration acceleration is processed, and the RMS value of vibration acceleration at $1 / 2$ octave is calculated, after which the road vibration level is calculated. The vibration level is optimized according to the human body's sensitivity to different frequencies of vibration, resulting in road service performance indicators that can reflect the human body's real feelings. According to the road service performance index values on the road grading, combined with GPS data on the electronic map color block labeling, the results obtained for the road condition warning, road maintenance, driver route selection have an important significance.

\section{Introduction}

The vibration caused by uneven impacts such as potholes and breaks in the road while the vehicle is in motion will affect the passenger's driving and riding comfort as well as the service life of the vehicle, and the resulting vibration and noise propagation will also have a greater impact on the surrounding residents and nearby buildings $[1,2]$. Therefore, timely and accurate labeling of road service performance research is of major importance and can promptly remind drivers to bypass the serious vibration road timely notice to the highway department to repair serious road damage.

Numerous experimental studies have shown that vibration can have profound effects on the human urinary, nervous, digestive, cardiovascular, and circulatory systems, and vision and hearing systems [3]. However, when the vehicle vibration information has specific distribution characteristics in space and time, existing research results often do not correctly reflect the tangible human feelings. For example, the currently prevailing international roughness index (IRI), defined as the cumulative displacement of the suspension system of a standard car traveling $1 \mathrm{~km}$ at a speed of $80 \mathrm{~km} / \mathrm{h}$ [4], is an averaging result, meaning that it is standardized to a spatial scale of $1 \mathrm{~km}$ regardless of the length of the actual test pavement. Griffin [5] points out that using the averaging algorithm in a small neighborhood of the main vibration information yields a very large value, while expanding this neighborhood to a large range may yield a very small value, and in both cases, anomalous results are obtained. Integration of vibration information using an averaging algorithm is oversimplified, and the various amplitude, transient, and shock vibration components of vibration information should be clearly defined. To avoid discussing the spatiotemporal distribution of vibration information, Miwa [6] proposed an index of vibration intensity values calculated in the pure frequency domain. Other indices calculated in the pure frequency domain include the roughness index of driving expenses for user costs such as vehicle depreciation, vehicle maintenance, and driving comfort [7] and the Michigan Driving Quality Index [8], which divides the long-, medium-, and short-wave 
longitudinal sections of the road surface into three components and computes them together. A large number of practices have shown that indicators calculated in the utter frequency domain lose information about the spatiotemporal distribution of vibrations, which can significantly affect actual ride comfort. To solve the problem of pure frequency domain indicators without spatiotemporal resolution, Ueckermann and Steinauer [9] used Fourier inverse conversion to convert the frequency domain content into a virtual weighted longitudinal cross section and jointly used the variance and extreme difference of this cross section for evaluation, but this did not fundamentally overcome the shortcomings of the variance or extreme difference indicators.

The collection of statistics on road irregularities is mostly official, and the official data collection is carried out using laser scanning vehicles to collect comprehensive information on the road surface. Although this method has high efficiency and accuracy, due to the constraints of human and material costs, it cannot be large-scale, high-frequency testing, and the timeliness of the collected road information is poor.

Some scholars have taken advantage of built-in accelerometers in mobile phones to measure road smoothness. Zhao et al. [10] used a genetic algorithm to analyze the acceleration and angular velocity data obtained only from mobile phone devices to estimate the road smoothness and pothole location. Existing studies mostly utilize bicycles bound to smart phones to collect road vibration data, and the processing process mostly uses the time domain acceleration amplitude to judge, missing the impact of different vibration frequencies on road service performance [11-14].

The relationship between driving discomfort and vibration acceleration was established experimentally by Huang and Dou [15], who concluded that vibrations with more high-frequency components $(>20 \mathrm{~Hz})$ caused more discomfort than vibrations with less high-frequency components. With the development of artificial intelligence technology, some scholars began to use the visual recognition method for road potholes and crack measurement [16-18]. However, the use of this method can only locate the size of cracks in the road under conditions of pavement deterioration and does not accurately measure road service performance.

In summary, how to examine the characteristics of the distribution of vibration information in space and time, so as to conduct a more accurate ride comfort evaluation, is a current problem.

\section{Calculation Method}

The human body can feel the vibration frequency range which is $1-1000 \mathrm{~Hz}$, the more sensitive vibration frequency range is $1-100 \mathrm{~Hz}$, vibration just felt is $0.003 \mathrm{~g}$, unpleasant vibration is $0.05 \mathrm{~g}$, and intolerable vibration is $0.5 \mathrm{~g}$. A large number of psychological and physiological experiments have shown that many vibrations are harmful to the human body, and the degree of harm to people is related to the way the vibration is transmitted to people and the characteristics of the vibration itself. The approach vibration is transmitted to people can be divided into overall vibration and local vibration, and its evaluation criteria are different. The vibrations generated by driving on uneven surfaces of the road are transmitted to the car through the wheels and suspension, causing environmental vibrations that support the human body. The effect on the human body is the overall vibration (also called whole body vibration), which is transmitted from the surface of the object to the human body.

Based on the subjective perception of vibration by the human body and the degree of harm vibration causes to the human body, international standards organizations (ISO2631) have proposed evaluation criteria, and various countries have also proposed their own standards on this basis. The evaluation criteria specify a frequency range of $1-90 \mathrm{~Hz}$. Vibration is divided into vertical and horizontal directions, suitable for sinusoidal, periodic, and random vibration, and the evaluation quantity adopts the effect of acceleration. In the environmental vibration analysis, the vibration level is usually used as the evaluation quantity whose unit is $\mathrm{dB}$, utilized to evaluate the vibration characteristics and vibration damping effect.

The human body has a close relationship with vibration sensation and amplitude, vibration frequency, vibration direction perpendicular, horizontal and rotational, vibration waveform, vibration exposure time, and so on. On the basis of a large number of time-measured vibration studies, the ISO2631 has come up with the human body's response curve to vertical and horizontal vibrations as shown in Figure 1.

As can be observed in Figure 1, for the overall vibration, the easiest to feel the vertical vibration frequency is $4-8 \mathrm{~Hz}$ and the easiest to feel the horizontal vibration frequency is $1-2 \mathrm{~Hz}$. For the vibration below $2.8 \mathrm{~Hz}$, it is easy to put up with the horizontal vibration, and above this frequency, it is sensitive to the vertical vibration. For vibration above $8 \mathrm{~Hz}$, the sensory level difference between vertical and horizontal vibration is $8 \mathrm{~dB}$.

The vibration level is an indicator to measure the impact of vibration on human beings based on the subjective response of human beings, and the effective amplitude of acceleration is corrected and weighted, which is defined as follows:

$$
\mathrm{VLz}=20 \lg \frac{a_{e}^{\prime}}{a_{0}} .
$$

The unit of $\mathrm{VLz}$ in the equation is $\mathrm{dB}$, where $a_{0}=1 \times 10^{-6} \mathrm{~m} / \mathrm{s}^{2}$ and $a_{e}$ (in $\mathrm{m} / \mathrm{s}^{2}$ ) is the effective value of acceleration, which can be calculated by the following equation:

$$
a_{e}^{\prime}=\sqrt{\frac{\sum a_{f e}^{2} \times 10^{\left(C_{f} / 10\right)}}{n}},
$$

where $a_{f e}$ (in $\mathrm{m} / \mathrm{s}^{2}$ ) is the effective value of vibration acceleration with the center frequency $f, n$ is the number of the center frequency, and $C_{f}$ is the corrected value shown in Table 1. 


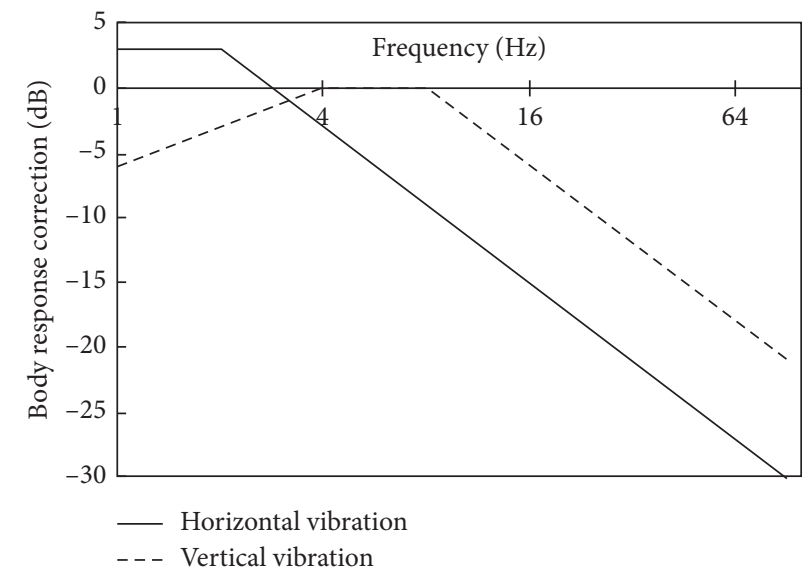

Figure 1: Human body response to different direction vibration.

TABLE 1: Modification value of vertical effective acceleration within the center frequency.

\begin{tabular}{lcccccc}
\hline Octave band center frequency $(\mathrm{Hz})$ & 1 & 2 & 4 & 8 & 16 & 31.5 \\
\hline Cutoff frequency $(\mathrm{Hz})$ & 1.4 & 2.8 & 5.6 & 11.2 & 22.4 & 45 \\
Vertical modified vibration power level $C_{f}(\mathrm{~dB})$ & -6 & -3 & 0 & 0 & -6 & -12 \\
\hline
\end{tabular}

The measurements and numerical simulation of environmental vibration are mostly carried out in the time domain, and the actual vibration is also a composite vibration of multiple spectra. In order to obtain the effective value of vibration acceleration for each spectrum, the Fourier transform of the vibration acceleration time scale obtained from the measurement or simulation is needed. In order to obtain the effective value of vibration acceleration of each frequency spectrum, it is necessary to carry out Fourier transform of the vibration acceleration duration obtained from measurement or simulation, whose process is called spectrum analysis.

Spectral analysis is obtained from the acceleration values of multiple frequencies, often using octave standard, a multiple of the central frequency, to calculate the vibration level. Based on the human body to feel the vibration level, the correction is made to obtain the vibration level before the vibration of each central frequency range is summed according to the energy.

The measured vertical vibration acceleration is spectrally transformed, filtered according to the upper and lower cutoff frequencies of the octave center frequency (as showed in Table 1) and the Fourier inverse change to the acceleration value of the frequency band, using equation (3) to calculate the effective value of vibration acceleration:

$$
a_{f e}=\sqrt{\frac{\sum a_{i}^{2}}{n}}
$$

where $a_{i}$ is the acceleration value at time $i$ in the frequency domain of the center frequency $f$.

\section{Data Collection}

In this paper, the vertical vibration acceleration as well as vehicle GPS information is collected by installing a multiaxis inertial navigation attitude sensor (shown in Figure 2) on the roof of a moving vehicle. The vibration sensor used in this paper has a high-precision gyroscope, accelerometer, geomagnetic field sensor, and GPS module, which can be efficient, accurate, stable acquisition of position and acceleration. According to the previous section, the human body is sensitive to vibration in the range of $1-100 \mathrm{~Hz}$, and the sampling frequency should be taken as $200 \mathrm{~Hz}$ because of the conjugate symmetry of the amplitude after Fourier transform. GPS returns one positioning data per second, and the road service performance evaluation interval is set as the distance travelled by the vehicle in one second.

The vehicle is in different pavement conditions when driving on the road, and the collection of vehicle vibration acceleration amplitudes is different. We found that two sections of service performance difference are large road sections during the road vibration acceleration collection process in Xuchang City, for road section-A and -B. Road section-A is asphalt concrete pavement, tertiary road, often over large trucks and the lack of necessary maintenance, resulting in serious damage to the pavement, as shown in Figure 3.

Vehicles driving in the road section-A can feel the severe bumps, and long-term driving on this road for the driving experience has a very bad impact, while the vehicle performance has a greater impact. As precipitation continues to hollow out the pavement subgrade will lead to further increases in damage if the road is not maintained in a timely manner, eventually leading to complete destruction of the road and the need for new construction. 


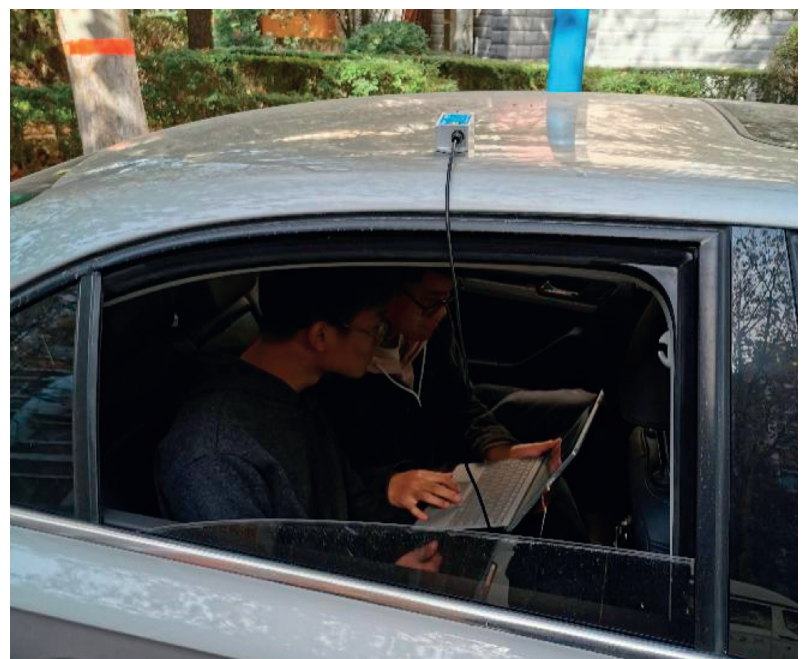

FIgURE 2: Roof-mounted acceleration sensors and data collection devices.

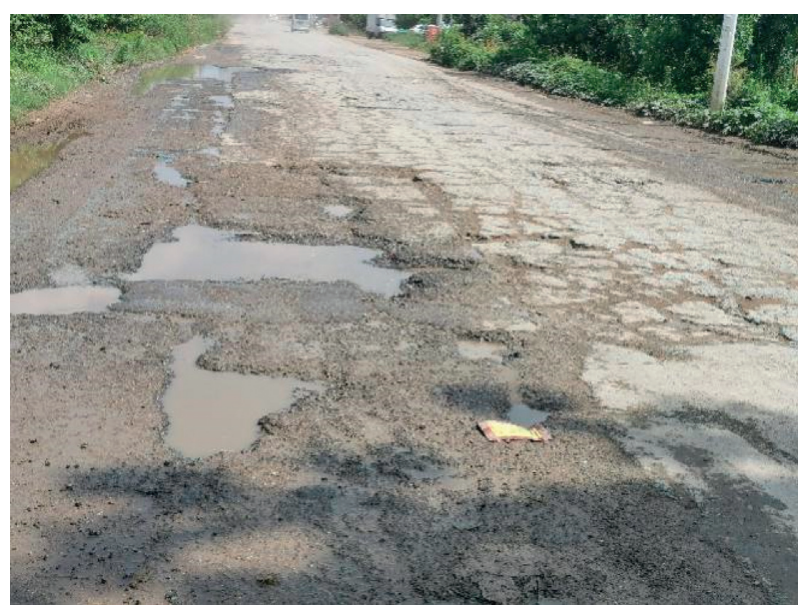

Figure 3: Road section-A.

Road section-B is located in the southern section of Xuchang City Expressway, which is part of the bypass expressway and belongs to the urban level 2 standards. This section of the road was previously severely damaged due to long-term truck loads and was recently repaired, with the surface layer resurfaced with asphalt concrete, as shown in Figure 4.

The road surface is smooth and there is not much traffic as it has just been repaired and opened to traffic. The ride on this section is smooth, with no significant vibration or noise, and the driving experience is good.

During the two road sections, the vibration acceleration collected by the accelerometer is shown in Figures 5 and 6 .

It is evident from the figure that the vertical vibration acceleration produced by the vehicle during travel in section- $B$ is much smaller than that produced during travel in section-A. The maximum vertical acceleration amplitude is close to $\pm 0.6 \mathrm{~m} / \mathrm{s}^{2}$ when driving in section- $A$, while in section- $\mathrm{B}$, the maximum vertical vibration acceleration amplitude is only $\pm 0.1 \mathrm{~m} / \mathrm{s}^{2}$.

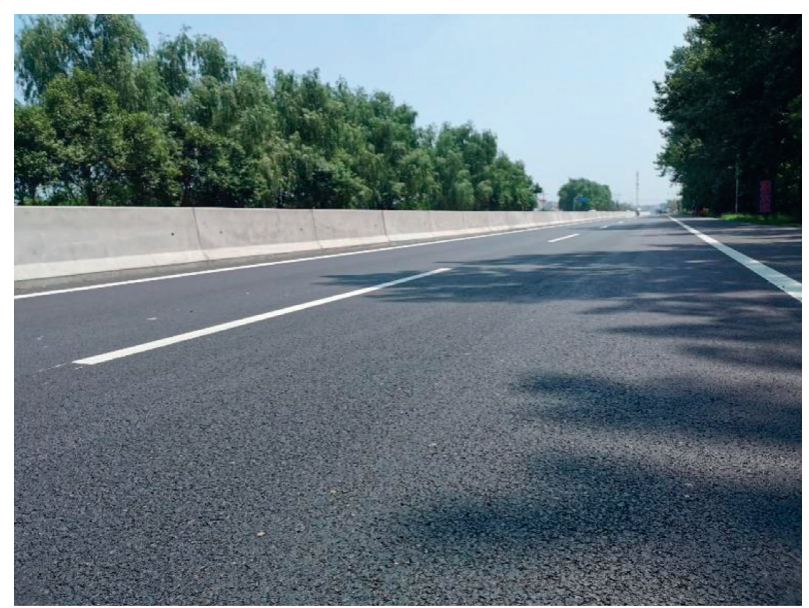

Figure 4: Road section-B.

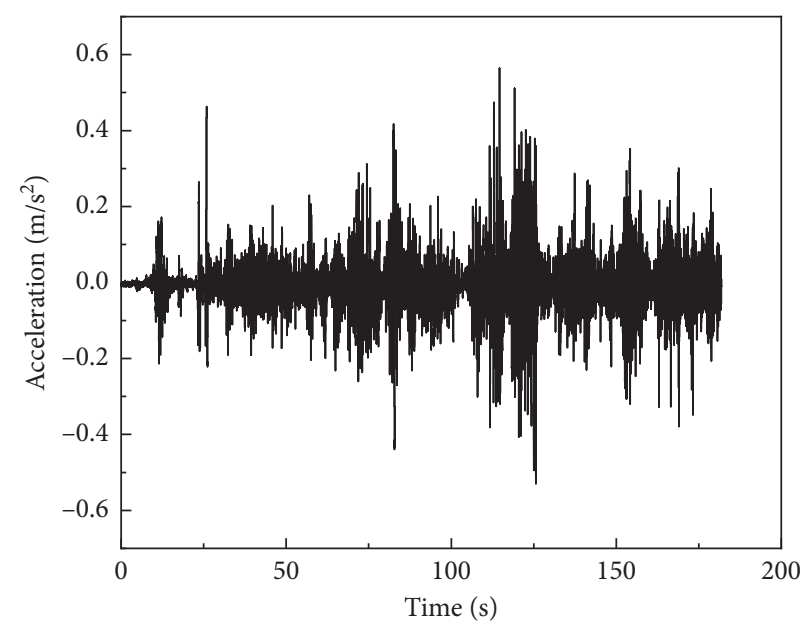

FIGURE 5: Vibration acceleration collected in section-A.

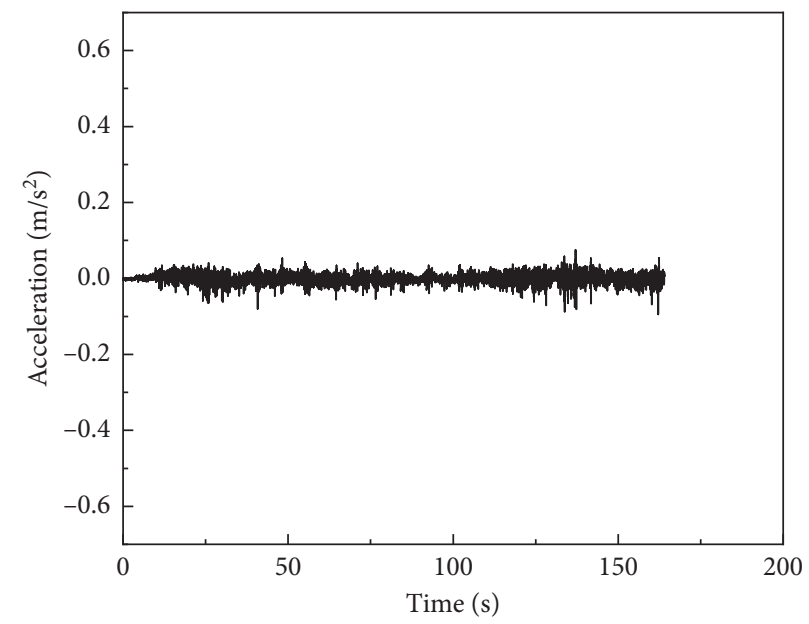

FIGURE 6: Vibration acceleration collected in section-B.

The maximum transient vibration value (MTVV) indicator can be used to integrate only the largest part of the vibration information and ignore other vibration information, which only integrates the largest vibration information 
within $1 \mathrm{~s}$. However, it has been proven that vibrations further than the maximum transient vibration information within $1 \mathrm{~s}$ can also significantly affect the actual discomfort, so the effect of using MTVV is not very good [19].

Using the calculation method described in Section 2 to calculate the vibration levels of the two road sections and based on the sensitivity of the human body to different frequencies of vibration optimization, the vibration levels of the two road sections are shown in Figure 7.

As can be seen from Figure 7, road section-A vibration level is significantly larger than the road section- $B$, and section-A in the vibration level of greater than $100 \mathrm{~dB}$ of the road section accounted for $42 \%$ of the entire road, while for section- $B$, there are only two larger vibrations, close to $95 \mathrm{~dB}$, located on the road surface drainage wells. As the drainage wells are recessed to a certain depth compared to the road surface, this results in a high level of vibration when vehicles drive over the covers, with generally low vibration in the remaining locations. At the beginning of the data collection, when the instrument was set up and the vehicle was started but not moving, the vibration was minimal.

As the damping effect varies from vehicle to vehicle, vibration data collected by vibration testers installed on different vehicles vary. The vibration level obtained after the acquisition and calculation is min-max normalization processing, the maximum value is $110.9 \mathrm{~dB}$ of the maximum vibration level in the acquisition area, and the minimum value is $79.34 \mathrm{~dB}$ of the minimum vibration level when the vehicle is running normally:

$$
V^{\prime}=\frac{V-V_{\min }}{V_{\max }-V_{\min }} .
$$

A road with a $V^{\prime}$ value of less than 0.33 is classified as a Class I road with a smoothness rating and excellent service performance. A road with a $V^{\prime}$ value between 0.3 and 0.66 is rated as a Class II for smoothness, with uneven, bumpy driving and average service performance. A road with a $V^{\prime}$ value greater than 0.66 is noted as Class III road with a damaged road surface, very bumpy ride, and poor service performance.

Marking the road service performance grading on the axes provides a clearer picture of the service performance of the entire road segment, as shown in Figure 8.

The measured Road A is longer than Road B, so the data collected on Road A are more than that on Road B. In order to clearly compare the vibration levels of the two roads, the same time interval should be selected to plot the vibration level distribution. It is obvious from the figure that Road A is mostly Class II and III roads, showing that driving on the road will produce larger bumps, while Road $B$ is basically a Class I road, only in the location of the road manhole cover and speed bumps appear higher bumps. The calculated road service performance rating is indicated in green, yellow, and red, combined with the corresponding GPS information marked on the map as shown in Figures 9 and 10, which can more intuitively show the degree of road bumps.

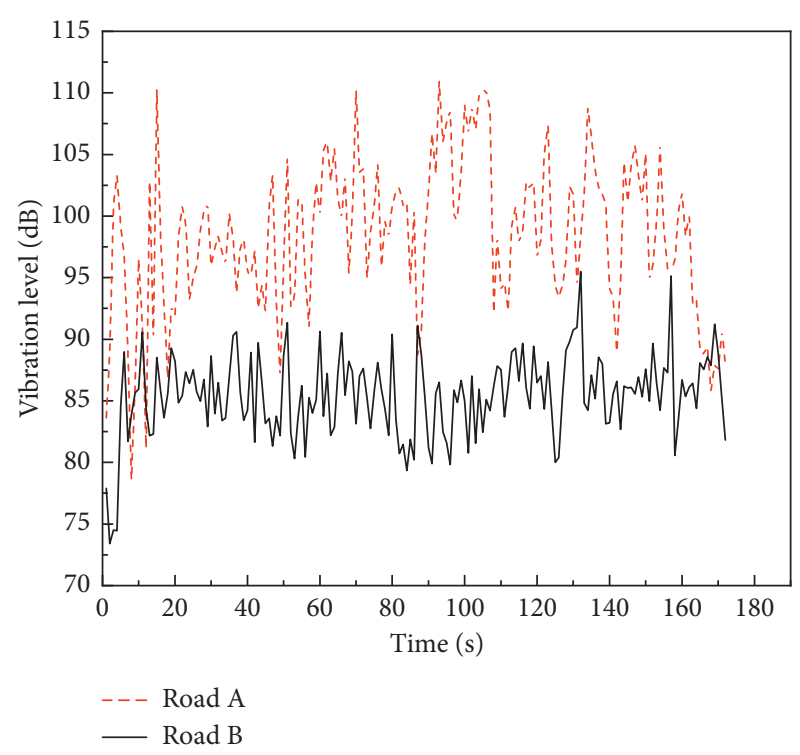

FIGURE 7: Vibration levels in two road sections.

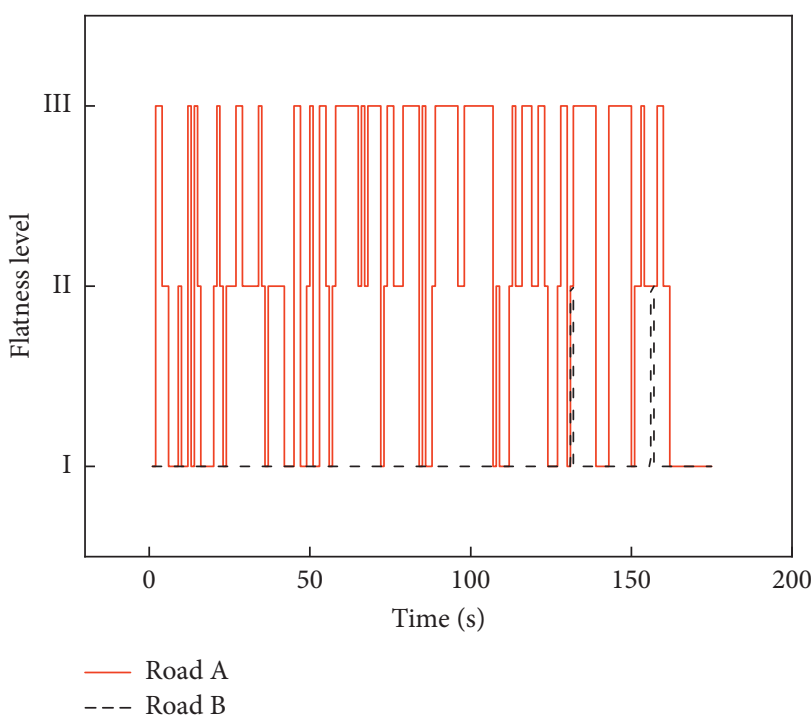

FIGURE 8: Service performance ratings for two road sections.

This method is used to evaluate the road service performance of some urban roads in Xuchang, Henan Province, and the results are shown in Figure 11.

From Figure 11, we can clearly see the quality of road service, but at present due to limited data collection, the above service performance map can only reflect the service performance of a certain lane of a road. In order to verify the correctness of the calculation results, the Road C shown in Figure 12 is selected as the validation section. The road section is located in the eastern suburbs of the city, where large vehicles are often driven and the road surface shows several damages. The road has all Class I, Class II, and Class III roads in the calculation results shown in Figure 13, which can visually verify the results of the calculation.

Both the $\mathrm{C} 1$ and $\mathrm{C} 3$ sections of the road exhibit heavy transverse penetration cracks, with the difference being that 


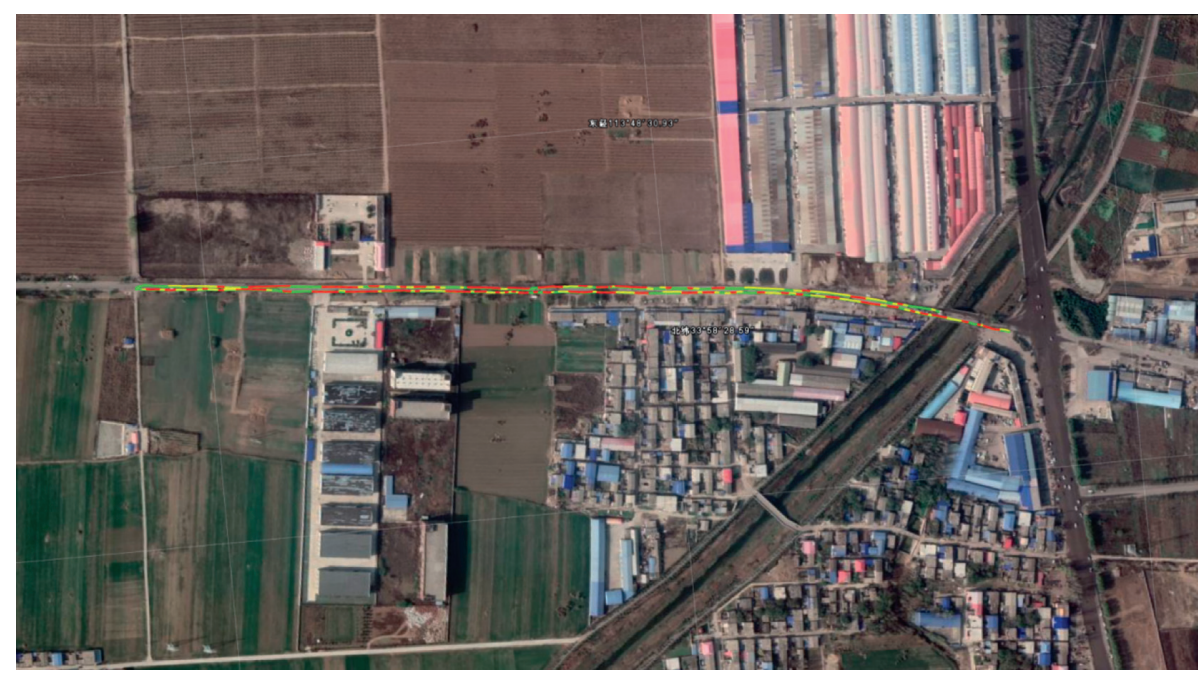

FIGURE 9: Road section-A service performance rating display chart.

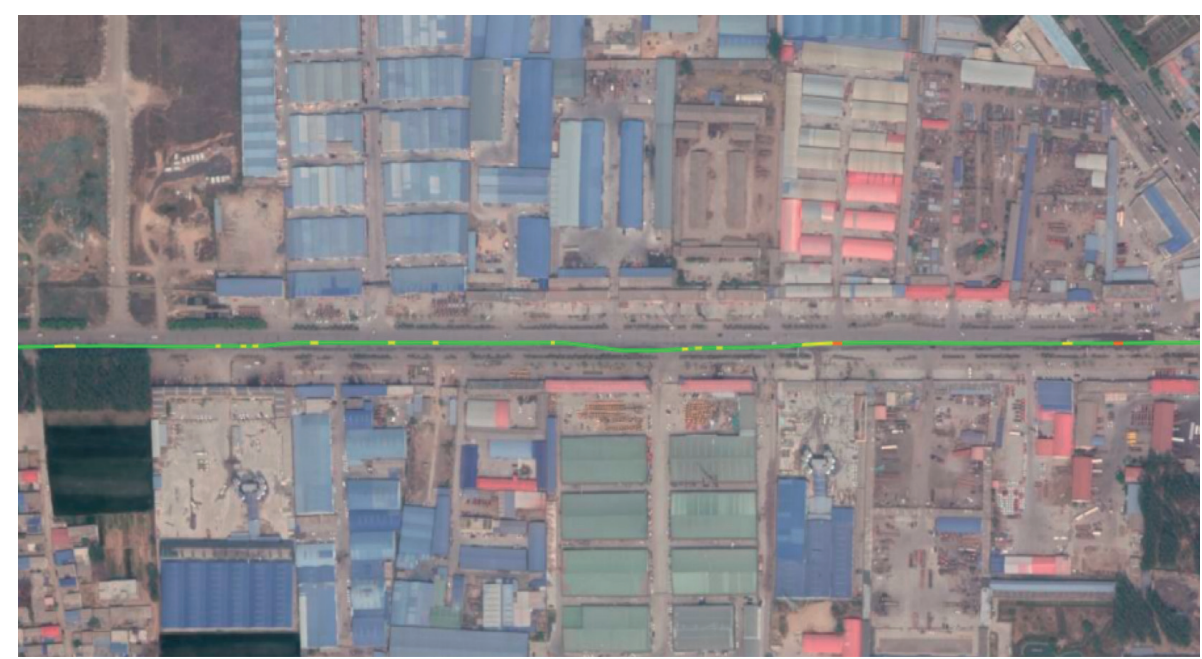

FIgURE 10: Road section-B service performance rating display chart.

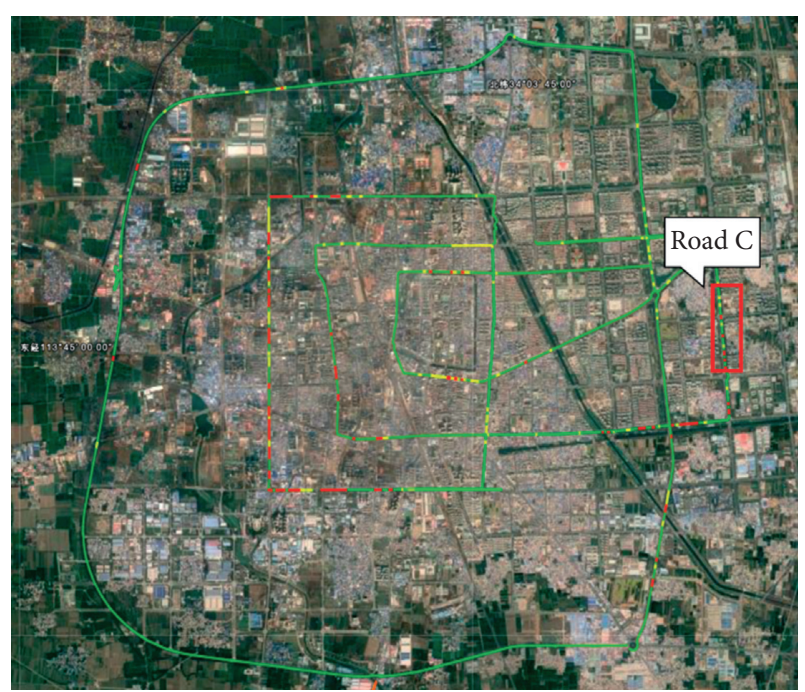

FIgURE 11: Xuchang City main road service performance map. the $\mathrm{C} 1$ section is partly repaired and passes more smoothly, with a calculated rating of Class II, while the C3 section is unrepaired and has a calculated rating of Class III. The C2 section passes smoothly and is rated as Class I. The C4 section exhibits cracking and vibrates more when driven to this location, which is rated as Class III. Through the above four road sections of the field verification, the accuracy of the method described in this paper is shown for the evaluation of road service performance.

In the future, vibration acquisition equipment can be installed on buses, taxis, sprinklers, and other vehicles in the city, combined with big data technology to evaluate the road service performance of the entire city, to help road maintenance departments to real-time monitoring of road conditions and timely maintenance of damaged roads. By combining rating data on service performance with mapping software to create an app, it can remind car owners to choose roads with better service performance and detour around poorer roads to improve driving experience. 


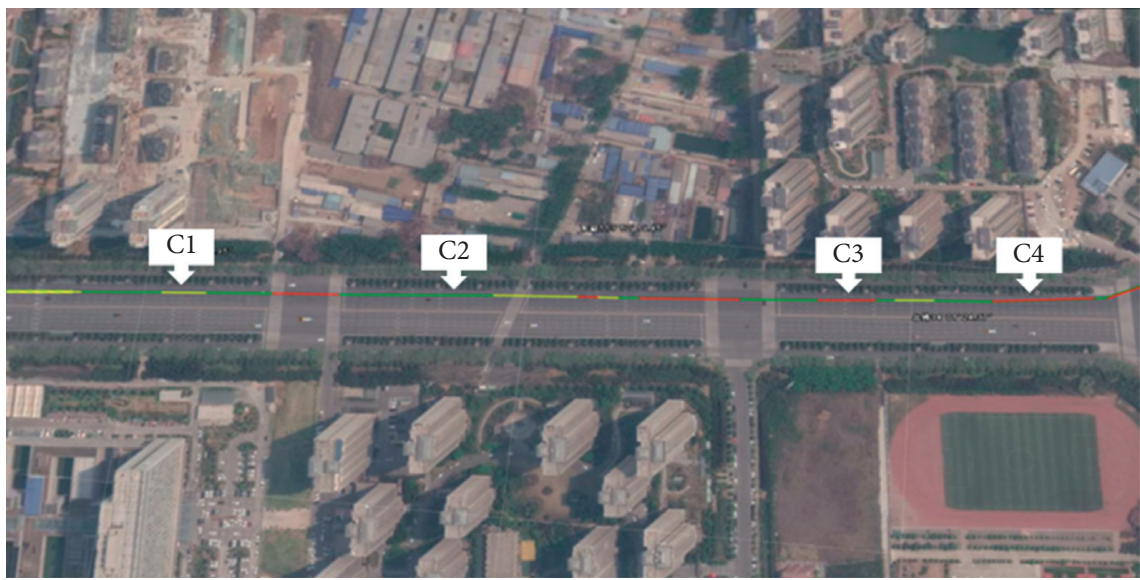

FIgURe 12: Validation section of Road C.
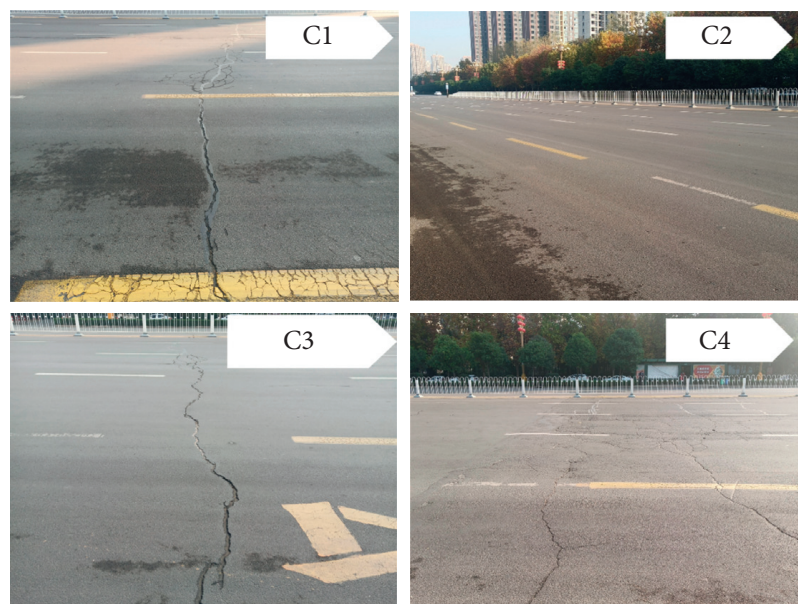

FIgURE 13: Field survey of road sampling (C1 C4).

\section{Conclusion}

From the above study, it can be concluded that the road vibration level map based on the human body's sensitivity to different frequencies of vibration can clearly and intuitively show the service performance of the road. The method is simple to collect and easy to calculate and is an efficient, simple, and inexpensive way to alert drivers and road maintenance units. The method is not limited to vehicles and can be placed on cars for service performance evaluation of urban road networks, and forest and mountain roads; it can also be used for bicycles for service performance evaluation of bicycle lanes. Its timeliness can overcome the increasing changes in road conditions, and the method enriches road smoothness measurement means and facilitates intuitive understanding and application by users, making vehicles into collection devices in daily use, which does not affect road use but also provide a new data source for open source geodatabase.

\section{Data Availability}

The data used to support the findings of this study are available from the corresponding author upon request.

\section{Conflicts of Interest}

The authors declare that they have no conflicts of interest.

\section{Acknowledgments}

The authors acknowledge the support from the National Key R\&D Program of China (2018YFB1600700) and Henan Youth Science Fund Project, and the authors are thankful to all the personnel who either provided the technical support or assisted in the data collection and processing.

\section{References}

[1] R. Klæboe, E. Öhrström, I. H. Turunen-Rise et al., "Vibration in dwellings from road and rail traffic-part III: towards a common methodology for socio-vibrational surveys," Applied Acoustics, vol. 64, no. 1, pp. 111-120, 2003.

[2] K. R. Czech, "The impact of the type and technical condition of road surface on the level of traffic-generated vibrations propagated to the environment," Procedia Engineering, vol. 143, pp. 1358-1367, 2016.

[3] J. Zhao, Research of Chinese Whole-Body Vibration Perception Thresholds, China Academy of Railway Sciences, Beijing, China, 2017.

[4] C. H. E. N. Zhang, Y. Liang, B. Xue, and L. Sun, "Relationship between vehicle vibration characteristics and human ride comfort," Journal of Tongji University(Natural Science), vol. 48, no. 07, pp. 1007-1015, 2020.

[5] M. J. Griffin, "A comparison of standardized methods for predicting the hazards of whole-body vibration and repeated shocks," Journal of Sound \& Vibration, vol. 215, no. 4, p. 883, 1998.

[6] T. Miwa, "Evaluation methods for vibration effect," Industrial Health, vol. 6, no. 1-2, pp. 11-17, 1968.

[7] A. T. Papagiannakis and B. Raveendran, "International standards organization-compatible index for pavement roughness," Transportation Research Record: Journal of the Transportation Research Board, vol. 1643, no. 1, pp. 110-115, 1998.

[8] S. M. Karamihas, Critical Profiler Accuracy requirements, University of Michigan-Transportation Research Institute, Ann Arbor, MI, USA, 2005. 
[9] A. Ueckermann and B. Steinauer, "The weighted longitudinal profile," Road Materials and Pavement Design, vol. 9, no. 2, pp. 135-157, 2008.

[10] B. Zhao, T. Nagayama, and K. Xue, "Road profile estimation, and its numerical and experimental validation, by smartphone measurement of the dynamic responses of an ordinary vehicle," Journal of Sound and Vibration, vol. 457, pp. 92-117, 2019.

[11] J. Gao, A. Sha, Y. Huang, L. Hu, Z. Tong, and W. Jiang, "Evaluating the cycling comfort on urban roads based on cyclists' perception of vibration," Journal of Cleaner Production, vol. 192, pp. 531-541, 2018.

[12] G. Singh, D. Bansal, S. Sofat, and N. Aggarwal, "Smart patrolling: an efficient road surface monitoring using smartphone sensors and crowdsourcing," Pervasive and Mobile Computing, vol. 40, pp. 71-88, 2017.

[13] V. Astarita, M. V. Caruso, G. Danieli et al., "A mobile application for road surface quality control: UNIquALroad," Procedia - Social and Behavioral Sciences, vol. 54, pp. 11351144, 2012.

[14] M. Y. Alam, A. Nandi, A. Kumar et al., "Crowdsourcing from the true crowd: device, vehicle, road-surface and driving independent road profiling from smartphone sensors," Pervasive and Mobile Computing, vol. 61, p. 101103, 2020.

[15] Y. U. Huang and L. Dou, "Subjective discomfort model of the micro commercial vehicle vibration over different road conditions," Applied Acoustics, vol. 145, no. 2, pp. 385-392, 2019.

[16] L. Huidrom, L. K. Das, and S. K. Sud, "Method for automated assessment of potholes, cracks and patches from road surface video clips," Procedia - Social and Behavioral Sciences, vol. 104, no. 2013, pp. 312-321, 2013.

[17] A. Tedeschi and F. Benedetto, "A real-time automatic pavement crack and pothole recognition system for mobile android-based devices," Advanced Engineering Informatics, vol. 32, pp. 11-25, 2017.

[18] A. M. Saad and K. N. Tahar, "Identification of rut and pothole by using multirotor unmanned aerial vehicle (UAV)," Measurement, vol. 137, pp. 647-654, 2019.

[19] N. J. Mansfield, P. Holmlund, and R. Lundström, “Comparison of subjective responses to vibration and shock with standard analysis methods and absorbed power," Journal of Sound and Vibration, vol. 230, no. 3, pp. 477-491, 2000. 